\title{
O tradutor e intérprete de Libras/Língua Portuguesa em espaços educacionais no Maranhão: uma análise discursiva de editais de concursos
}

Walquiria Pereira da Silva Dias ${ }^{1}$

Resumo: As reflexões apresentadas neste trabalho são um recorte de uma pesquisa de mestrado centrada na constituição do sujeito tradutor e intérprete de Libras/Língua Portuguesa (TILP) em documentos oficiais. Objetivamos analisar, a partir das nomenclaturas, requisitos e atribuições para o cargo de TILP em editais de concurso do Estado do Maranhão. Para fundamentar nossas reflexões, utilizamos pressupostos teóricos da Análise do Discurso foucaultiana. Diante das análises realizadas, constatamos que o sujeito TILP tem se constituído a partir de tensões entre os discursos institucionais e as vivências advindas das possibilidades de atuação do TILP, uma relação de poder que atravessa os enunciados linguístico-discursivos dos editais de concurso para TILP no Maranhão.

Palavras-chave: Tradutor e intérprete de Libras/Língua Portuguesa. Documentos oficiais. Discurso. Resistências.

Abstract: The reflections presented are a cut of a master's research focused on the constitution of the subject translator and interpreter of Libras / Portuguese Language (TILP) in official documents. We aim to analyze, from the nomenclatures of the positions of public notices and the requirements and attributions, the speeches that cross linguistic materiality. To base our reflections, we use theoretical assumptions from the French Discourse Analysis and from Michel Foucault. Considering the analyzes carried out, we note that the TILP occupies an institutional place derived from struggles and resistances based on the discourse of inclusion.

Keywords: Translator and interpreter of Libras / Portuguese Language. Official documents. Speech. Resistors.

Resumen: Las ideas presentadas son un recorte de la investigación de maestría que se centró en la constitución del sujeto traductor e intérprete de Libras / portugués (TILP) en los documentos oficiales. Objetivamos analizar, a partir de las nomenclaturas de los cargos de edictos de concurso y de los requisitos y atribuciones, los discursos que atraviesan la materialidad lingüística. Para fundamentar nuestras reflexiones, utilizamos presupuestos teóricos del análisis del discurso francés y de Michel Foucault. Ante los análisis realizados, notamos que el TILP ocupa un lugar institucional oriundo de luchas y resistencias basadas en el discurso de inclusión.

Palabras clave: Traductor e intérprete de Libras / portugués. Documentos oficiales. Discurso. Resistencias.

\footnotetext{
${ }^{1}$ Tradutora-intérprete de Libras do curso Letras-Libras. Professora-intérprete de Libras de São José de Ribamar. Mestrado em Letras.
} 


\section{Introdução}

O debate sobre o tradutor-intérprete de Libras/Língua Portuguesa (TILP²) ganha fôlego no campo discursivo das políticas de inclusão para as pessoas surdas, ou seja, o processo de inclusão social dos surdos funciona como mola propulsora da profissionalização do TILP, tendo em vista que a função exercida parte da necessidade de comunicação entre surdos e ouvintes nos vários espaços sociais.

Com a promulgação da Lei no 10.436 , de 24 de abril de 2002, e, principalmente com o Decreto no 5.626, de 22 de dezembro de 2005, o direito linguístico dos sujeitos surdos é reafirmado e, consequentemente, o movimento em prol de uma profissionalização do TILP ganhou legitimidade. Ainda que a presença desse profissional se dê em setores diferenciados, é na educação que possui maior visibilidade. Portanto, cabe refletirmos como tem se dado as políticas públicas nessa área, tendo como ponto de partida a garantia do profissional tradutor e intérprete de Libras/Língua Portuguesa nas instituições educacionais.

Consideramos que os documentos oficiais refletem movimentos históricos e discursivos acerca da inclusão de surdos, sendo necessário, portanto, compreendermos as práticas discursivas e não discursivas que os atravessam. Dessa maneira, tomamos como objeto de análise os editais de concursos da rede estadual do Maranhão (2009 e 2015), da Universidade Federal do Maranhão - UFMA (2009 e 2013) e do Instituto Federal de Educação, Ciência e Tecnologia do Maranhão - IFMA (2014 e 2016). Desses documentos, serão considerados a nomenclatura, requisitos e atribuições dos cargos para TILP.

Nessa direção, caminhando pelas veredas foucaultianas, em que o discurso é concebido como uma prática, cuja ordem responde às verdades de uma época (FOUCAULT, 2014a; 2014b), objetivamos analisar os discursos e as práticas não discursivas a partir do cargo de TILP na esfera federal e do cargo de professorintérprete da rede estadual, lugares institucionais distintos, a partir de uma rede de

\footnotetext{
${ }^{2}$ Sabemos que na literatura a sigla mais utilizada é TILSP (tradutor e intérprete de língua de sinais e língua portuguesa). Em nossa pesquisa optamos por utilizar TILP marcando o par linguístico Libras/Língua Portuguesa e, portanto, especificamente dos profissionais atuantes nessa área.
} 
saberes alinhavada nas condições históricas de inclusão dos surdos no Maranhão e do processo de profissionalização do TILP no Estado.

\section{A nomenclatura e os atravessamentos discursivos}

As travessias históricas que sustentam a subjetivação do sujeito TILP advêm do discurso de valorização da Língua Brasileira de Sinais (Libras) e de participação social dos surdos, tendo como linha de força o poder discursivo da política. O dispositivo político permite a inserção da pessoa com deficiência nas discussões sobre inclusão/exclusão, transformando-a em sujeito de direitos e, no caso da pessoa surda, a acessibilidade comunicativa por meio da Libras. Eis o pano de fundo de um discurso de valorização da Libras que se movimenta e é legitimado pelo dispositivo jurídico.

Por dispositivo, Foucault (2016) denomina os ditos e os não ditos, o discursivo e o não discursivo que orienta a vida dos sujeitos, produzindo saberes e subjetividades. Os documentos oficiais, portanto, atuam como reguladores da vida social, como dispositivos que instituem verdades segundo ordens discursivas específicas (CARVALHO; SARGENTINI, 2014). Nessa perspectiva, tomamos os editais citados como materialidades que estabelecem práticas profissionais que subjetivam o TILP em posições-sujeito ${ }^{3}$ distintas e, consequentemente, trazem reflexões sobre o processo de inclusão dos surdos nos espaços educacionais.

Nesse contexto, os cargos nos editais do Estado e nos editais federais possuem denominações diferentes (tabela 1).

Tabela 1: Editais e respectivas nomenclaturas

\begin{tabular}{|c|c|c|}
\hline DISPOSITIVOS OFICIAIS & TERMINOLOGIA & SETORES \\
\hline $\begin{array}{l}\text { Editais dos concursos da } \\
\text { Secretaria de Educação do } \\
\text { Estado /SEGEP-SEDUC (2009 }\end{array}$ & $\begin{array}{l}\text { - Professor-Intérprete } \\
\text { de Libras }\end{array}$ & - Educação \\
\hline
\end{tabular}

\footnotetext{
${ }^{3}$ Lugares a serem ocupados pelo sujeito conforme uma ordem discursiva. "As diversas modalidades de enunciação em vez de remeterem para a síntese ou a função unificadora de um sujeito, manifestam a sua dispersão. Nos diversos lugares, nas diversas posições que pode ocupar ou receber quando sustenta o discurso" (FOUCAULT, 2014a, p. 93).
} 


\begin{tabular}{|l|l|l|l|}
\hline e 2015) & & \\
\hline $\begin{array}{l}\text { Editais dos concursos } \\
\text { Universidade Federal do } \\
\text { Maranhão (2009) }\end{array}$ & $\begin{array}{l}\text { - Tradutor intérprete } \\
\text { de Linguagem de Sinais }\end{array}$ & - Técnico-administrativo \\
\hline $\begin{array}{l}\text { Editais dos concursos } \\
\text { Universidade Federal do }\end{array}$ & $\begin{array}{l}\text { - Tradutor Intérprete } \\
\text { de Linguagem de Sinais } \\
\text { Maranhão (2013) }\end{array}$ & - Técnico-administrativo \\
\hline $\begin{array}{l}\text { Editais dos concursos do drador Intérprete } \\
\text { Instituto Federal do } \\
\text { Maranhão (2014 e 2016) }\end{array}$ & $\begin{array}{l}\text { - Tradutor e Intérprete } \\
\text { de LIBRAS }\end{array}$ & - Técnico-administrativo \\
\hline
\end{tabular}

Fonte: Elaborada pela autora.

Conforme a tabela, a divisão do TILP se estabelece em dois campos de saber principais: a educação e a área técnica, ainda que tratem de funções da mesma natureza, ou seja, exercidas em salas de aula, ressalvadas as demandas de cada nível de ensino (educação básica e ensino superior). No primeiro grupo, o TILP localiza-se em uma posição-sujeito ligada ao processo de ensino-aprendizagem e, portanto, é considerado um professor (editais estaduais). No segundo grupo, localizamos os editais federais, para quem o TILP é um profissional técnico-administrativo.

No lugar institucional de técnico, tendo em vista o nível de ensino e dos alunos surdos, a função do TILP distancia-se de possíveis intervenções no processo de ensinoaprendizagem, ainda que isso ainda seja possível. Trata-se de posições-sujeito orientadas para atuações que se cruzam (traduzir e interpretar), mas que ativam outros saberes em torno das questões trabalhistas,

Considerado um profissional da educação, o TILP apresenta uma especificidade educacional. A atuação educacional possui singularidades inerentes ao campo do saber pedagógico, isto é, são necessárias competências e habilidades referenciais, linguísticas, tradutórias/interpretativas e pedagógicas. A natureza do processo de ensino-aprendizagem, a dinâmica institucional e o nível de ensino interferem diretamente na prática interpretativa (LACERDA, 2010; MARTINS, 2013, 2016). A atuação nos espaços educacionais vai além da sala de aula, “[...] pondo em contato sujeitos, práticas e saberes que exigem tomadas de decisão e posicionamentos dos TILPs” (DIAS, 2018, p. 90). De acordo com Martins (2013, p. 144, grifos da autora):

Faz-se necessário marcar que o posicionamento, ou seja, a maneira ativa de estar na relação [...]. O aluno surdo interfere no posicionamento do intérprete 
e, consequentemente, na posição demarcada na sala de aula (para além da posição corporal do intérprete, embora, até o aspecto da escolha física, da cadeira ou de estar em pé ao lado do aluno ou do professor, são questões que influenciam as relações de sala de aula e tais escolhas têm sobremaneira interferências e é dotado de saberes sobre sua atuação) pelo intérprete, a marca de estar ali e de fazer parte do processo, com certeza interfere na relação com o aluno surdo, professor e com os demais colegas [...].

$\mathrm{Na}$ instituição educacional, há surdos, docentes, TILPs, discentes ouvintes e demais membros envolvidos no processo. Sujeitos e realidades distintas, experiências que representam a complexidade da atuação em contextos de ensino, o que gera uma heterogeneidade da posição-sujeito do TILP nos diversos níveis. Desse modo, a atuação do TILP no ambiente acadêmico direciona-se mais para o ato de traduzir e interpretar, focando na função de intermediar a comunicação entre professor e discentes surdos. Diferentemente, na educação básica, a prática do TILP é influenciada por questões pedagógicas e pelas dificuldades linguísticas e sociais do discente surdo (RODRIGUES; SILVÉRIO, 2011; GESSER, 2015; MARTINS, 2016). Assim, dependendo desses fatores, o TILP atuante na educação básica busca outras estratégias metodológicas para passar o conteúdo que está sendo trabalhado, não exatamente apenas se utilizando da interpretação da fala do professor regente. Rodrigues e Silvério (2011, p. 46) afirmam:

Enquanto a educação infantil e os anos iniciais do Ensino Fundamental exigem a presença de professores bilíngues atuando em codocência, dito de outro modo, enquanto nesses níveis há a necessidade de uma atuação educacional, no sentido de que o "intérprete" mais ensina do que interpreta, nos demais níveis há uma atuação que se concentra mais na interpretação e na colaboração com o professor, sendo que nesses níveis mais avançados o $\mathrm{IE}^{4}$ não assume a função de professor.

Desses discursos em torno das diversas funções assumidas pelo TILP no espaço educacional, emergem práticas não discursivas e que compõem o conjunto de políticas inclusivas das pessoas surdas. Na posição-sujeito de profissional da educação, o TILP tem direitos e deveres trabalhistas semelhantes aos professores (editais estaduais), como, por exemplo, a carga horária semanal de $20 h$, resguardadas as horas de planejamento, portanto 13h de efetivo trabalho em sala, o que contribui na redução do esforço físico. Na posição-sujeito de técnico-administrativo, esse direito não é assegurado, passando a carga horária semanal para 4oh, efetivando uma atividade

\footnotetext{
${ }^{4}$ Intérprete educacional.
} 
interpretativa sobrecarregada e comprometendo a qualidade do serviço prestado, em consequência, a aprendizagem dos surdos.

Cabe salientar que a carga horária citada justifica-se pela natureza da função (professor-intérprete $\mathrm{x}$ tradutor-intérprete), mas traz às discussões o questionamento da natureza do trabalho. Dito de outro modo, ainda que sejam cargos distintos ambos sinalizam, interpretam, traduzem, utilizam esforço físico e cognitivo, portanto as possibilidades do desgaste são as mesmas. Nesse sentido, a carga horária excessiva potencializa prováveis problemas de saúde.

A atuação profissional do TILP traz à mesa dos debates outra prática não discursiva marcada por relações de poder entre a empiria dos TILPs e as normas institucionais: o revezamento na interpretação, caracterizado pela necessidade de um intérprete de apoio de modo que diminua o cansaço físico e cognitivo. Quanto a essa prática, a Federação Brasileira das Associações dos Profissionais Tradutores e Intérpretes e Guia-Intérpretes de Língua de Sinais (FEBRAPILS) orienta que a permuta seja em média de 20 a 3omin (nota técnica no 02-2017). De acordo com a Norma Regulamentadora no 17 - Ergonomia, publicada pelo Ministério do Trabalho (item 17.6.3): "Nas atividades que exijam sobrecarga muscular estática ou dinâmica do pescoço, ombros, dorso e membros superiores e inferiores [...]" devem ser realizadas pausas para descanso e, em caso de afastamento, o retorno gradativo.

A relação de saber-poder existente entre a empiria dos TILPs, haja vista que são eles que possuem conhecimento da sua área de atuação e por isso possuem poder para argumentar, e as determinações institucionais geram momentos de tensões e resistências tendo em vista a posição-sujeito de técnicos administrativos, já que, na maioria das instituições federais, além da carga horária mencionada, não é garantido o revezamento. No caso das instituições estaduais do Maranhão, não há um revezamento, mas a carga horária é reduzida, permitindo menos dias de trabalho. Vale ressaltar que não há uma prática única, cada instituição federal possui uma dinâmica de trabalho, logo são lutas e experiências singulares que subjazem a atuação do TILP como pertencente ao quadro dos técnicos-administrativos.

A dinâmica de trabalho em revezamento não está estabelecida em dispositivos oficiais, mas se justifica com a prática profissional, o que nos permite afirmar a relevância das vivências dos TILPs, concebidas como fontes de novos saberes e 
comportamentos, servindo de objeto de regulamentação nos ambientes institucionais e em documentos oficiais futuros. A dinamicidade das normas advém dos focos de experiências a partir de práticas discursivas inscritas na história.

[...] focos de experiência, nos quais se articulam uns sobre os outros: primeiro, as formas de um saber possível; segundo, as matrizes normativas de comportamento para os indivíduos; e enfim os modos de existência virtuais para sujeitos possíveis. Esses três elementos - formas de um saber possível, matrizes normativas de comportamento, modos de existência virtuais para sujeitos possíveis -, são essas três coisas, ou antes, é a articulação dessas três coisas que podemos chamar, creio, de "foco de experiência" (FOUCAULT, 2010, p. 4-5).

A categoria conceitual foco de experiência permeia os caminhos históricos do TILP, de maneira que a profissionalização desse sujeito deriva de vivências que geraram práticas e saberes sobre a atuação. A partir das experiências dos primeiros intérpretes ${ }^{5}$ novas práticas trabalhistas foram surgindo, novas matrizes normativas foram ganhando visibilidades. O revezamento é fruto desses focos de experiência e, como já dissemos, não é uma realidade de todos os Estados, não está legalmente determinado. Assim, o revezamento aparece como efeito de negociação com os setores de lotação, a partir da iniciativa dos TILPs enquanto sujeitos que possuem conhecimento de causa e sentem na pele a necessidade de permuta.

Martins e Nascimento (2015) corroboram o valor das experiências em um diálogo com a ergologia, pondo a tradução e interpretação como uma atividade de trabalho. Nessa esteira, a prática produz verdades e institucionaliza normas.

A normalização de uma atividade e a institucionalização de um saber, nesse prisma, não pode desconsiderar que as normas, mesmo com toda a sua importância, não são suficientes para a realização da atividade. Elas são frutos de aparição em um determinado momento histórico que pode ser sempre questionado e feito, portanto, uma genealogia. De uma perspectiva ergológica, a inexistência delas coloca o sujeito em um vácuo, um vazio a ser gerido, mas a supervalorização, ao contrário, aprisiona o sujeito que, com o peso delas, vive situações dramáticas tornando o seu trabalho invisível (MARTINS; NASCIMENTO, p. 105).

\footnotetext{
${ }^{5}$ Inicialmente essa era a denominação, ainda não se pensava o intérprete no campo da tradução.
} 
No embate entre os saberes sujeitados ${ }^{6}$ (FOUCAULT, 1999) e os saberes institucionais que perpassam as questões trabalhistas do TILP como técnicoadministrativo emergem outras demandas, tal como a necessidade de investimento financeiro para contratação de mais profissionais, por isso mais gastos com recursos humanos. Além disso, percebemos um desconhecimento (ou indiferença) do esforço físico e cognitivo da função ${ }^{7}$, o que leva a embates entre os saberes empíricos dos TILPs e as práticas institucionais. Essas relações de poder se manifestam no intuito de disciplinar a atuação do sujeito TILP, gerando resistências desse profissional frente às práticas trabalhistas ainda não oficializadas, mas empoderadas nos focos de experiências (DIAS, 2018).

No tocante ao Professor-intérprete, a realidade maranhense reflete enfrentamentos político-discursivos dos intérpretes contratados e militantes da área, representados pela Associação dos Profissionais Tradutores/Intérpretes de Língua Brasileira de Sinais do Maranhão (APILMA), pelo Centro de Apoio à Pessoa com Surdez (CAS) e pela Associação de Surdos do Maranhão. As jornadas de trabalho exaustivas vivenciadas pelos TILPs contratados foram objeto de discussões na organização do edital nº01/2009 referente ao primeiro concurso do Estado para TILP, concentrando o cargo no grupo de professores, considerando a dinâmica da atuação na educação básica e garantindo melhores condições de trabalho.

A análise do discurso trabalhista, das práticas institucionalizadas e das relações de poder-saber geradas a partir das nomenclaturas nos permite dialogar com saberes acerca das atribuições estabelecidas nos editais conforme as condições sócio-históricas em que aparecem.

\section{Requisitos e atribuições: um olhar para a prática profissional}

\footnotetext{
6 Termo analisado por Foucault (1999) sob várias perspectivas. Nesse trabalho, interessa-nos o seguinte entendimento: "Por 'saberes sujeitados', eu entendo igualmente toda uma série de saberes que estavam desqualificados como saberes não conceituais, como saberes insuficientemente elaborados [...] esse saber que denominarei, se quiserem, o 'saber das pessoas'” (FOUCAULT, 1999, p. 12).

${ }^{7}$ Essa análise parte de experiências como TILP e do conhecimento da realidade de outros profissionais tradutores e intérpretes de Libras/Língua Portuguesa.
} 
A legislação e as produções que compõem a literatura sobre a tradução e interpretação das línguas de sinais validam práticas discursivas que apontam o TILP enquanto profissional mediador da comunicação entre surdos e ouvintes. Essa posiçãosujeito é objeto de regulamentação dos documentos oficiais, entre eles os editais de concurso. Observamos como a denominação do cargo gera uma análise discursiva que transborda os enunciados linguísticos alcançando questões trabalhistas. Nesse ponto, realizamos a análise dos requisitos e das atribuições, observando como o TILP é discursivizado e que práticas não discursivas podem ser problematizadas no processo de inclusão de pessoas surdas nos espaços educacionais.

No Edital n.o 01/2009, da Secretaria de Educação do Estado do Maranhão (SEDUC), o Professor - Intérprete de Libras é dividido em dois grupos: formação de ensino médio e formação superior.

Quadro 1: Cargo e atribuições, segundo o edital do Estado (2009).

\begin{tabular}{|c|c|}
\hline FORMAÇÃO / REQUISITOS & ATRIBUIÇÕES \\
\hline $\begin{array}{l}\text { Curso de Formação de } \\
\text { Professor em Ensino Médio em } \\
\text { Magistério, na Modalidade } \\
\text { Normal, acrescido de Curso de } \\
\text { Libras com carga horária de no } \\
\text { mínimo 12oh. }\end{array}$ & $\begin{array}{l}\text { - Fazer tradução e interpretação da Língua } \\
\text { Portuguesa para Libras de todas as áreas de } \\
\text { conhecimento do currículo das séries iniciais do } \\
\text { ensino fundamental em escolas inclusivas da rede } \\
\text { pública estadual. } \\
\text { - Intermediar a comunicação entre interlocutores } \\
\text { surdos e ouvintes em situações do cotidiano } \\
\text { escolar. } \\
\text { - Prestar serviços em seminários, cursos e reuniões } \\
\text { e/ou outros eventos de formação continuada, } \\
\text { quando solicitado. } \\
\text { - Realizar outras atribuições compatíveis com sua } \\
\text { especialização profissional. }\end{array}$ \\
\hline $\begin{array}{l}\text { Licenciatura Plena em qualquer } \\
\text { área, acrescido de Curso de } \\
\text { Libras com carga horária de no } \\
\text { mínimo } 12 \mathrm{oh} \text {. }\end{array}$ & $\begin{array}{l}\text { - Fazer tradução e interpretação da Língua } \\
\text { Portuguesa para Libras de todas as áreas de } \\
\text { conhecimento do currículo da educação básica em } \\
\text { escolas inclusivas da rede pública estadual. } \\
\text { - Intermediar a comunicação entre interlocutores } \\
\text { surdos e ouvintes em situações do cotidiano } \\
\text { escolar. } \\
\text { - Prestar serviços em seminários, cursos e reuniões } \\
\text { e/ou outros e eventos de formação continuada, }\end{array}$ \\
\hline
\end{tabular}




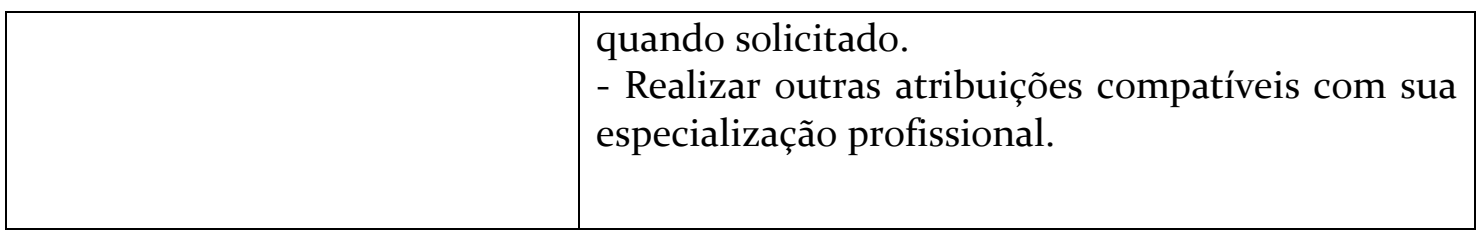

Fonte: Edital no 01/2009 (SEDUC-MA).

Esse concurso suscitou debates sobre a atuação do TILP, já que permitiu a inscrição para dois cargos de níveis, formações e salários diferentes, mas com as mesmas atribuições. O professor-intérprete de nível médio atuaria no ensino fundamental e o professor-intérprete de nível superior atuaria no ensino médio.

Primeiramente, voltemos o olhar para a função de professor, portanto uma responsabilidade no processo de ensino-aprendizagem que não deve ser negligenciada e exige uma formação para atuar na área. No entanto, os requisitos para o cargo silenciam a qualidade da educação inclusiva das pessoas surdas, haja vista que possibilita a inscrição em um cargo de nível médio. Nessa perspectiva, ter profissionais sem uma formação adequada atuando na educação como professores ou outras funções que interferem no processo de ensino-aprendizagem, à primeira vista, é fechar os olhos para uma educação de qualidade, com profissionais qualificados. Por outro lado, responde a uma ordem social na qual havia poucos profissionais formados e com habilidades necessárias para atuar com discentes surdos, o que justifica o requisito do cargo possibilitando que muitos intérpretes contratados e sem formação pudessem ser efetivados no serviço público.

Outro ponto de análise corresponde à demanda do Estado, que não propiciou a divisão exata estabelecida no edital. Assim, muitos professores-intérpretes de nível médio foram nomeados e lotados para atuar no ensino médio, possuindo as mesmas funções que os professores-intérpretes de nível superior, mas com remunerações diferentes $^{8}$. Esse fator foi reforçado pela mudança da responsabilidade pelo ensino fundamental, de exclusividade dos municípios. Assim, todos os professores-intérpretes passariam a atuar nas escolas de responsabilidade do Estado, portanto no mesmo nível. Essas matrizes normativas (FOUCAULT, 2010) geraram mudanças no Edital no o1/2015 cujas vagas foram organizadas para um cargo único: Professor-intérprete de Libras, nível superior. As atribuições permaneceram as mesmas do Edital no o1/20o9.

\footnotetext{
${ }^{8}$ Informação empírica, oriunda da atuação como professora-intérprete no período de 2010 a 2013.
} 
Quadro 2: Formação e atribuições, segundo o edital do Estado (2015).

\begin{tabular}{|c|c|}
\hline FORMAÇÃO / REQUISITO & ATRIBUIÇÕES \\
\hline 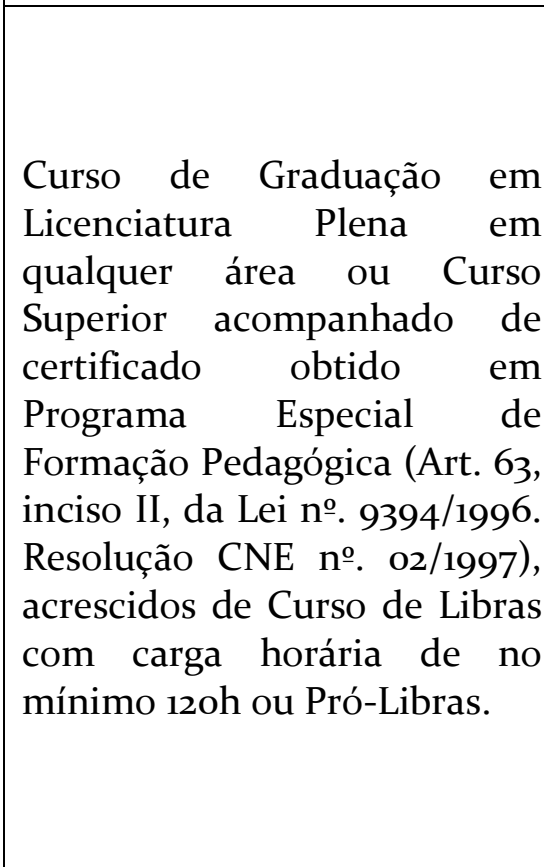 & $\begin{array}{l}\text { Traduzir e interpretar Libras/Português/Libras; } \\
\text { Fazer tradução e interpretação da Língua } \\
\text { Portuguesa para a Libras de todas as áreas do } \\
\text { conhecimento do currículo da educação básica em } \\
\text { escolas da rede pública estadual; Intermediar a } \\
\text { comunicação entre interlocutores surdos e ouvintes } \\
\text { em situações do cotidiano escolar; Prestar serviços } \\
\text { em seminários, cursos e reuniões e/ou outros } \\
\text { eventos de formação continuada, quando solicitado, } \\
\text { inclusive nos momentos de planejamento do } \\
\text { professor, a fim de otimizar o conteúdo específico } \\
\text { de cada disciplina relacionando sempre com o ato } \\
\text { de interpretar; Participar ativamente das atividades } \\
\text { do cotidiano escolar, atentando sempre para a } \\
\text { intermediação dos diálogos envolvendo estudantes } \\
\text { com surdez em situações diversas. Realizar outras } \\
\text { atribuições compatíveis com sua formação } \\
\text { profissional. }\end{array}$ \\
\hline
\end{tabular}

Fonte: Edital no o1/2015 (SEGEP-MA).

Podemos destacar dois tópicos principais: a mudança no requisito e o acréscimo de atribuições. Quanto aos requisitos, a exigência do curso Magistério Normal foi substituído pelo Curso Superior, quaisquer cursos, porém com uma complementação pedagógica, o que demarca o poder do dispositivo educacional, em que é necessário possuir uma formação pedagógica para atuar no âmbito educativo. A formação é reforçada pelo Certificado de Proficiência em Libras (PROLIBRAS). Mais uma vez cabe salientar a dinâmica política e social do Estado do Maranhão, cujo número de TILPs formados em tradução/interpretação-bacharelado, determinação do Decreto no 5.626/2005, é insuficiente. Logo, o edital não restringiu para a formação de bacharelado e optou pelo curso de Libras ou PROLIBRAS como títulos que validam a competência da prática interpretativa.

Nas atribuições, notamos a determinação para o TILP participar dos momentos de planejamento. Essa determinação é proveniente de práticas de trabalho marcadas pela não participação dos professores-intérpretes nas reuniões de planejamento. Quando essa prática torna-se objeto de regulamentação, reitera o discurso que legitima 
o saber do TILP permitindo-lhe interagir com os professores das disciplinas curriculares e participar mais ativamente do processo educacional dos surdos, de maneira a orientar nas estratégias metodológicas e compartilhar conhecimentos correspondentes a Libras, aos surdos e temas afins.

Essa prática discursiviza um sujeito que produz saberes no ambiente educacional, com uma função pedagógica, e converge com a nomenclatura (professorintérprete), ratificando as singularidades desse lugar institucional, diferentemente do técnico-administrativo, cuja prática se restringe à intermediação linguística a partir da interpretação e a intervenção pedagógica é mais rara.

A participação do TILP nos planejamentos, nos conselhos de classe e em formações continuadas para a equipe pedagógica ainda é uma matriz normativa em desenvolvimento. O planejamento autoriza o sujeito TILP a intervir em um espaço que produz discursos de enfrentamento diante das necessidades das pessoas surdas, resistências diversas. Vale ressalvar que a própria presença de surdos nas escolas é uma ação de resistência. Sobre a participação do TILP no planejamento e as implicações dessa prática, Santos, Diniz e Lacerda (2016, p. 139) afirmam:

O que pudemos observar é que quando as relações são favoráveis fora da sala de aula - no momento do planejamento, em diálogo com outros profissionais, na elaboração de materiais -, a interpretação simultânea em sala de aula se torna menos complexa. É preciso estabelecer parcerias no espaço educacional; assim como o professor tem uma série de momentos de preparo de material e aulas, encontros e discussões com outros professores para troca de experiências, o $\mathrm{IE}^{9}$ deve contar com esses momentos para refletir sobre sua prática, dialogar de forma aprofundada com outros profissionais que conheçam e discutam as experiências.

Buscando dialogar com as análises foucaultianas, entendemos o planejamento como uma ferramenta que valida o saber sujeitado dos TILPs, produzindo uma matriz comportamental, uma vez que legitima os saberes oriundos da prática profissional, permitindo que o TILP participe de espaços que antes não ocupava. O discurso de valorização desse profissional na dinâmica pedagógica se materializa nos editais na redação das atribuições.

A esfera federal realizou em 2009 o primeiro concurso para Tradutor-Intérprete de Linguagem de Sinais para atuar na UFMA. Conforme frisamos, diferente do edital

\footnotetext{
${ }^{9}$ Intérprete educacional, nomenclatura utilizada também por Rodrigues e Silvério (2011).
} 
estadual o cargo faz parte do grupo de técnicos-administrativos. No fim de 2013, um novo concurso foi anunciado pela mesma instituição. Vamos analisar os requisitos e atribuições, de acordo com os respectivos editais.

Quadro 3: Formação e atribuições de acordo com os editais da UFMA.

\begin{tabular}{|c|c|c|c|c|}
\hline EDITAL & CARGO & & FORMAÇÃO & ATRIBUIÇÕES \\
\hline $\begin{array}{ll}\text { Edital } & \text { GR } \\
1 / 2009, & \text { de } \\
16 & \text { de } \\
\text { janeiro } & \text { de } \\
2009 . & \\
\end{array}$ & $\begin{array}{l}\text { Nível D } \\
\text { Tradutor } \\
\text { Intérprete } \\
\text { Linguagem } \\
\text { Sinais. }\end{array}$ & $\begin{array}{l}\text { de } \\
\text { de }\end{array}$ & $\begin{array}{l}\text { Ensino } \\
\text { completo } \\
\text { proficiência } \\
\text { LIBRAS. }\end{array}$ & $\begin{array}{l}\text { Traduzir e interpretar a } \\
\text { linguagem de sinais. }\end{array}$ \\
\hline \multirow[t]{2}{*}{$\begin{array}{l}\text { Edital PRH } \\
\text { № } 1 / 2013 \text {, } \\
\text { de } 13 \text { de } \\
\text { dezembro } \\
\text { de } 2013 \text {. }\end{array}$} & \multicolumn{2}{|l|}{$\begin{array}{l}\text { Nível E } \\
\text { Tradutor } \\
\text { Intérprete. }\end{array}$} & 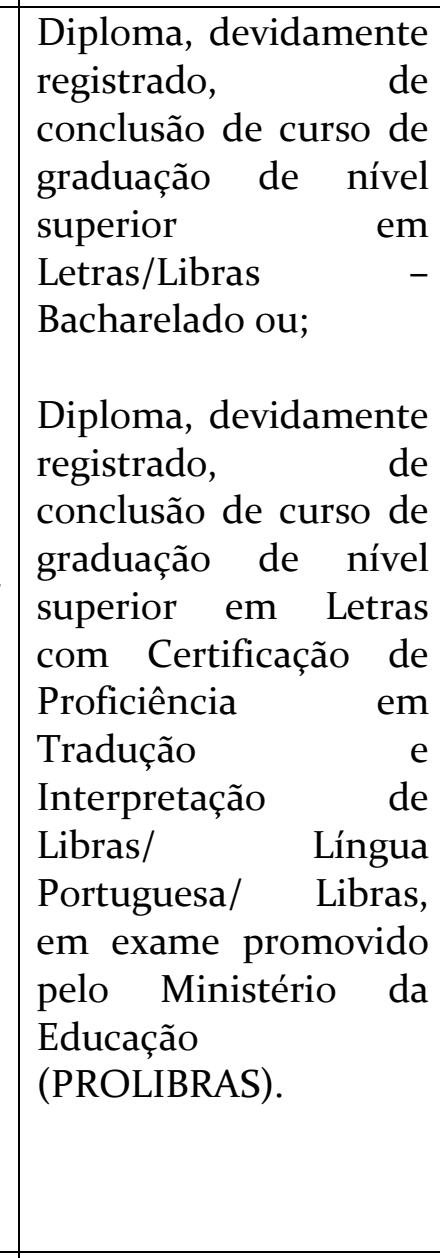 & $\begin{array}{l}\text { Traduzir, na forma } \\
\text { escrita, textos de qualquer } \\
\text { natureza, de um idioma } \\
\text { para outro, considerando } \\
\text { as variáveis culturais, bem } \\
\text { como os aspectos } \\
\text { terminológicos } \\
\text { estilísticos, tendo em vista } \\
\text { um público-alvo } \\
\text { específico. Interpretar } \\
\text { oralmente, de forma } \\
\text { simultânea ou } \\
\text { consecutiva, de um } \\
\text { idioma para outro, } \\
\text { discursos, debates, textos } \\
\text { e formas de comunicação } \\
\text { eletrônica, respeitando o } \\
\text { respectivo contexto e as } \\
\text { características culturais } \\
\text { das partes; tratar das } \\
\text { características e do } \\
\text { desenvolvimento de uma } \\
\text { cultura, representados por } \\
\text { sua linguagem. Assessorar } \\
\text { nas atividades de ensino, } \\
\text { pesquisa e extensão. }\end{array}$ \\
\hline & $\begin{array}{l}\text { Nível D } \\
\text { Tradutor } \\
\text { Intérprete } \\
\text { Linguagem } \\
\text { Sinais. }\end{array}$ & & $\begin{array}{l}\text { Ensino } \\
\text { completo } \\
\text { proficiência } \\
\text { LIBRAS. }\end{array}$ & $\begin{array}{l}\text { Traduzir e interpretar a } \\
\text { linguagem de sinais. }\end{array}$ \\
\hline
\end{tabular}

Fonte: Editais GR 1/2009 e PRH no o1/2013 (UFMA). 
Os editais de concurso da UFMA surgiram da força discursiva das políticas inclusivas e são assentadas em condições de emergência específicas. O primeiro concurso foi uma forma de regularizar a função de TILP que ocorria por meio de contrato, no intuito de atender o primeiro discente surdo aprovado em Contabilidade, no ano de 2008. Com o aumento da demanda nos anos seguintes, foi realizado o segundo concurso.

De acordo com o quadro 3, o edital de 2013 trouxe dois cargos com formação e remunerações distintas: ensino médio (nível D) e superior (nível E). Na atuação prática não há diferenças. Essa distinção de níveis dos cargos representa uma polêmica atual baseada na dinâmica de mercado, ou seja, os concursos para nível D justificam-se em uma ordem social caracterizada por um grande número de intérpretes sem formação superior. Na atualidade, essa justificativa não se sustenta. Porém, as instituições aparam-se nas fissuras da legislação e na inexistência de regulamentações oficiais quanto à atuação do TILP. Segundo Dias (2018, p. 101):

\begin{abstract}
No contexto maranhense, existem cursos de especialização em Tradução e Interpretação, mas somente em 2014 concretizou-se uma formação superior específica (Tradução-Interpretação em Libras/ Bacharelado). A UFMA, em parceria com a Universidade Federal de Santa Catarina (UFSC), implantou um polo do Curso de Letras-Libras à distância: licenciatura e bacharelado, com 30 vagas cada, ocupadas, em sua maioria, por intérpretes atuantes nos mais diversos setores. Em 2015, foi estabelecido o Curso de Licenciatura em Letras/Língua Brasileira de Sinais, na modalidade presencial, possibilitando a formação de profissionais qualificados para atuarem na educação básica, mas apenas como licenciados. Esse fato representa um acontecimento discursivo em que as discussões políticas sobre os surdos adentram a universidade, caracterizando uma conquista para os surdos do Maranhão. Porém, não se direciona para o bacharelado, o que traz reflexões sobre a formação dos tradutores e intérpretes de Libras/Língua Portuguesa do Estado, uma necessidade do mercado de trabalho local, cuja demanda é significativa.
\end{abstract}

A abertura dos cursos de Letras-Libras está previsto no Plano Nacional dos Direitos da Pessoa com Deficiência (Viver sem Limites), refletindo uma ordem discursiva assinalada pelo investimento das políticas públicas na inclusão das pessoas com deficiência. Logo, o contexto maranhense reverbera a realidade social brasileira marcada pelo movimento político de inclusão das pessoas surdas.

O Instituto Federal de Educação, Ciência e Tecnologia do Maranhão (IFMA) realizou concursos em 2014 e 2016, seguindo as mesmas discursividades da UFMA. 
Quadro 4: Formação e atribuições de acordo com os editais do IFMA (2014 e 2016).

\begin{tabular}{|c|c|c|c|}
\hline EDITAL & CARGO & REQUISITOS & ATRIBUIÇÕES \\
\hline $\begin{array}{l}\text { Edital } n^{\circ} \\
\text { o1/ } 2014\end{array}$ & $\begin{array}{l}\text { Tradutor } \\
\text { Intérprete } \mathrm{d} \\
\text { LIBRAS }\end{array}$ & $\begin{array}{l}\text { Ensino Médio } \\
\text { Completo e Certificado } \\
\text { de proficiência em } \\
\text { LIBRAS. }\end{array}$ & \\
\hline $\begin{array}{l}\text { Edital } \text { no }^{\circ} \\
02 / 2016\end{array}$ & $\begin{array}{l}\text { Tradutor } \\
\text { Intérprete } \mathrm{d} \\
\text { LIBRAS }\end{array}$ & 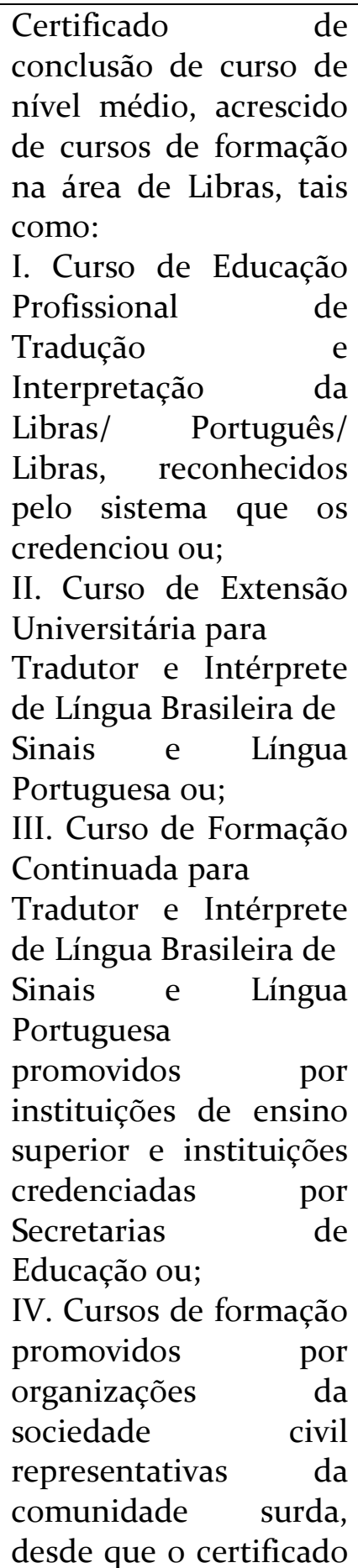 & $\begin{array}{l}\text { Traduzir e interpretar } \\
\text { artigos, livros, textos } \\
\text { diversos de um idioma para } \\
\text { o outro, bem como traduzir } \\
\text { e interpretar palavras, } \\
\text { conversações, narrativas, } \\
\text { palestras, atividades } \\
\text { didático-pedagógicas em } \\
\text { outro idioma, } \\
\text { reproduzindo LIBRAS ou } \\
\text { na modalidade oral da } \\
\text { Língua Portuguesa o } \\
\text { pensamento e intenção do } \\
\text { emissor. Assessorar nas } \\
\text { atividades de ensino, } \\
\text { pesquisa e extensão. }\end{array}$ \\
\hline
\end{tabular}




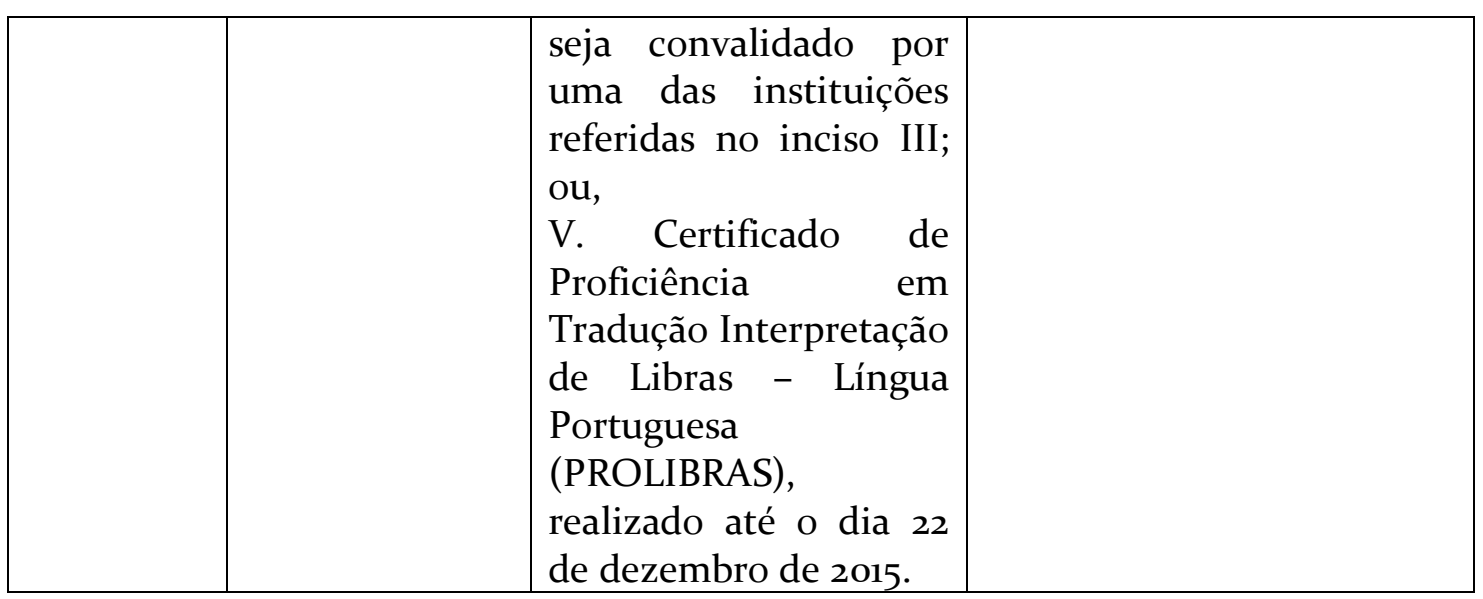

Fonte: Editais 1/2014 e no 02/2016 (IFMA).

Apesar de reconhecer a necessidade de formações específicas e apoiar a institucionalização do saber empírico por meio da titulação de Proficiência em Libras, os editais do IFMA singularizam o novo na repetição: novos editais, novas vagas no mercado de trabalho, mas os mesmos enunciados linguístico-discursivos de outros editais para TILP nível D. Esse fator constitui um campo associado com o discurso político, econômico e a instabilidade jurídica que baliza a profissão.

O discurso econômico em convergência com o discurso político produz verdades e práticas institucionalizadas que atuam como cernes de conflitos e resistência. Acerca da relação verdade-economia-política, Foucault afirma (2016, p. 52):

\begin{abstract}
Em nossas sociedades, a "economia política" da verdade tem cinco características historicamente importantes: a "verdade" é centrada na do discurso científico e nas instituições que o produzem; está submetida a uma constante incitação econômica e política (necessidade de verdade tanto para a produção econômica, quanto para o poder político; é objeto, de várias formas, de uma imensa difusão e de um imenso consumo (circula nos aparelhos de educação ou de informação, cuja extensão no corpo social é relativamente grande, não obstante algumas limitações rigorosas); é produzida e transmitida sob o controle, não exclusivo, mas dominante, de alguns grandes aparelhos políticos ou econômicos (universidade, Exército, escritura, meios de comunicação); enfim, é objeto de debate político e de confronto social (as lutas "ideológicas").
\end{abstract}

Os enunciados linguístico-discursivos dos editais mostram como o TILP vem sendo discursivizado nas fendas legislativas, gerando práticas não discursivas balizadas por conflitos. Os concursos geralmente partem de uma necessidade emergencial e divergem conforme as decisões da Administração Pública (CAMARGO; ALBRES, 2012). 
O discurso de inclusão das pessoas surdas alicerça a legislação e as práticas institucionais da educação das pessoas surdas, mas esbarra no discurso e nas práticas institucionais (editais de concurso) que afetam negativamente a profissionalização do TILP, processo inacabado e constituído em ações de resistência e poder.

\section{Considerações finais}

$\mathrm{Na}$ análise discursiva dos editais de concursos da rede estadual do Maranhão (2009 e 2015), da UFMA (2009 e 2013) e do IFMA (2014 e 2016), buscamos relacionar os discursos e as práticas sociais que permeiam a profissionalização do TILP e atuação nos espaços educacionais. A análise dos processos de concursos para TILP constitui um objeto bem atual e nos permite reflexões quanto à inclusão/exclusão de surdos no campo educacional, haja vista que os conflitos originados da atuação do TILP ecoam nesse processo.

O panorama atual da educação de surdos é proveniente de uma série de práticas discursivas e não discursivas fundadas na empiria e em uma conjuntura sócio-histórica que estabelece quem pode ou não (requisitos e atribuições) ocupar as posições-sujeito de professor-intérprete e tradutor-intérprete (técnico). Cada posição-sujeito constituise na relação saber-poder que disciplina e fabrica o sujeito TILP (DIAS, 2018).

Os dispositivos oficiais dispersam discursos sobre o TILP e permitem caminhos de análises diversos, conforme o olhar do analista do discurso. Portanto, as discussões que realizamos não se esgotam, mas funcionam como uma peça em uma rede de múltiplos saberes e olhares.

\section{Referências}

BRASIL. Decreto no 5.626, de 22 de dezembro de 2005. Regulamenta a Lei no 10.436, de 24 de abril de 2002, que dispõe sobre a Língua Brasileira de Sinais - Libras, e o art. 18 
da Lei no 10.098, de 19 de dezembro de 2000. Disponível em: <http://www.planalto.gov.br/ccivil_03/_ato2004-2006/2005/decreto/d5626.htm>. Acesso em: o1 ago. 2018.

. Decreto $n^{\circ}$ 7.612, de 17 de novembro de 2011. Institui o Plano Nacional dos Direitos da Pessoa com Deficiência - Plano Viver sem Limites. Disponível em: <http://www.planalto.gov.br/ccivil_03/_ato2011-2014/2011/decreto/d7612.htm>. Acesso em: 10 fev. 2018.

. Lei no 10. 436, de 24 de abril de 2002. Dispõe sobre a Língua Brasileira de Sinais - Libras e dá outras providências. Disponível em: <http://www.planalto.gov.br/CCIVIL_03/Leis/2002/L10436.htm>. Acesso em: o1 ago. 2017.

CAMARGO, A. C. S. Concurso público para intérprete educacional: saberes determinados para os candidatos - conjuntura nacional. In: ALBRES, N. A.; SANTIAGO, V. A. A. (Orgs.). Libras em estudo: tradução/interpretação. São Paulo: FENEIS, 2012. p. 75-107. Disponível em: <http://feneis.org.br/wpcontent/uploads/2016/o5/Libras-em-Estudo-Tradu\%C3\%A7\%C3\%A3o-

Interpreta\% $\mathrm{C}_{3} \% \mathrm{~A}_{7} \% \mathrm{C}_{3} \% \mathrm{~A}_{3}$ o.pdf>. Acesso em: 11 ago. 2017.

CARVALHO, P. H. V.; SARGENTINI, V. M. O.. Dispositivo, discurso e subjetividades. In: FERNANDES JÚNIOR, A.; SOUSA, K. (Orgs.). Dispositivos de poder em Foucault: práticas e discursos da atualidade. Goiânia: Gráfica UFG, 2014· p. 23-34.

DIAS, W. P. S.. Travessias e resistências: práticas de subjetivação do sujeito tradutor e intérprete de Libras/Língua Portuguesa nos documentos oficiais. 2018. 125 p. Dissertação (Mestrado em Letras). Universidade Federal do Maranhão, UFMA. São Luís. Disponível em: <https://tedebc.ufma.br/jspui/handle/tede/2189>. Acesso em: 10 set. 2018.

FEDERAÇÃO BRASILEIRA DAS ASSOCIAÇÕESDOS PROFISSIONAIS TRADUTORES E INTÉRPRETES E GUIA-INTÉRPRETES DE LÍNGUA DE SINAIS. Nota Técnica sobre a contratação do serviço de interpretação de Libras/Português e profissionais intérpretes de Libras/Português (no $n^{-}$02/2017). Disponível em: <https://drive.google.com/file/d/oB3eZNKrWC6hcWnAyd 3 FlU2VFQmc/view>. Acesso em: o1 ago. 2018. 
FOUCAUlT, M. A arqueologia do saber. Tradução: Miguel Serras Pereira. 70. ed. Lisboa: Almedina, 2014a. 271 p.

. A ordem do discurso: aula inaugural no Collège de France, pronunciada em 2 de dezembro de 1970. Tradução: Laura Fraga de Almeida Sampaio. 24. ed. São Paulo: Edições Loyola, 2014b. 74 p.

. Em defesa da sociedade: curso no Collège de France (1975-1976). Tradução Maria Ermantina Galvão. São Paulo: Martins Fontes, 1999. p. 3-48.

. Microfísica do poder. 4. ed. Rio de Janeiro: Paz e Terra, 2016.

. O governo de si e dos outros: curso no Collège de France (1982-1983). Tradução

Eduardo Brandão. São Paulo: Martins Fontes, 2010. p. 4-23.

GESSER, A. Interpretar ensinando e ensinar interpretando: posições assumidas no ato interpretativo em contexto de inclusão para surdos. Caderno de Tradução, v. 35, no especial 2, p. 534-556, jul-dez, 2015. Disponível em: <https://periodicos.ufsc.br/index.php/traducao/article/view/21757968.2015V35nesp2p534>. Acesso em: o9 jan. 2018.

INSTITUTO FEDERAL DE EDUCAÇÃO, CIÊNCIA E TECNOLOGIA DO MARANHÃO. Edital no oo1, de 7 de abril de 2014. Concurso Público para Provimento de Cargos Efetivos da Carreira Técnico Administrativa em Educação. São Luís, MA. Disponível em: <https://eloconcursos.com.br/_arquivos/diversos/files/oo-edital-concurso-ifma2014.pdf>. Acesso em: 05 dez. 2016.

INSTITUTO FEDERAL DE EDUCAÇÃO, CIÊNCIA E TECNOLOGIA DO MARANHÃO. Edital no 02, de 26 de agosto de 2016. Concurso Público para Provimento de Cargos Efetivos da Carreira dos Cargos Técnico-Administrativos em Educação. São Luís, MA. Disponível em: <https://www.fsadu.org.br/c/1232/get_doc.php?id=2\&c=e68507ebbba8cb553ee7b6e19o 750of705c58346>. Acesso em: o5 dez. 2016.

LACERDA, C. B. F. Tradutores e intérpretes de Língua Brasileira de Sinais: formação e atuação nos espaços inclusivos. Cadernos de Educação, n. 36, Pelotas, p. 133-153, maio/agosto. 2010. Disponível em: <https://periodicos.ufpel.edu.br/ojs2/index.php/caduc/article/viewFile/1604/1487>. Acesso em: 7 jan. 2018. 
MARANHÃO. Edital nº 01/2009. Concurso Público para Cargos de Professores da Educação Básica (Ensino fundamental, Ensino regula e Educação Especial). Secretaria de Estado da Administração e Previdência Social.

. Edital SEGEP no 01/2015. Concurso Público de Provas e Títulos para Professor da Educação Básica da Secretaria de Estado da Educação. Disponível em: <http://www.ma.gov.br/wp-content/uploads/2015/11/Edital_oo1_SEGEP-

SEDUC_2015.pdf >. Acesso em: o5 dez. 2016.

MARTINS, V. R. O. Posição Mestre: desdobramentos foucaultianos sobre a relação de ensino do Intérprete de Língua de Sinais Educacional. (Tese). Doutorado em Educação. Universidade de Campinas, Campinas/SP, 2013. Disponível em: <http://repositorio.unicamp.br/bitstream/REPOSIP/250830/1/Martins_VanessaRegina deOliveira_D.pdf>. Acesso em: o1 nov. 2017.

. Tradutor e intérprete de língua de sinais educacional: desafios da formação. Belas Infiéis, v. 5, n. 1, p. 147-163, 2016. Disponível em: <http://periodicos.unb.br/index.php/belasinfieis/article/view/19513>. Acesso em: 10 fev. 2018.

; NASCIMENTO, V. Da formação comunitária à formação universitária (e vice e versa): novo perfil dos tradutores e intérpretes de língua de sinais no contexto brasileiro. Caderno de Tradução, Florianópolis, v. 35, no especial 2, p. 78-112, jul-dez, 2015. Disponível em: $<$ https://periodicos.ufsc.br/index.php/traducao/issue/view/2296/showToc>. Acesso em: 01 ago. 2018.

RODRIGUES, C. H.; SILVÉRIO, C. C. P. Interpretando na educação: quais conhecimentos e habilidades o intérprete educacional deve possuir? Espaço: informativo técnico-científico do INES. Rio de Janeiro, n. 35, jan/jul, 2011. p. 42-50. Disponível

em:

<https://ead2.moodle.ufsc.br/pluginfile.php/119489/mod_resource/content/o/RODRI GUES\%2C\%202011.pdf>. Acesso em: 15 jun. 2017.

SANTOS, S. A. A implementação do serviço de tradução e interpretação de LibrasPortuguês nas universidades federais. Caderno de Tradução, Florianópolis, v. 35, no especial 2, p. 113-148, jul-dez, 2015. Disponível em: 
$<$ https://periodicos.ufsc.br/index.php/traducao/issue/view/2296/showToc>. Acesso em: 07 jan. 2018.

UNIVERSIDADE FEDERAL DO MARANHÃO. Edital GR 1/2009, de 16 de janeiro de 2009. Concurso Público para Pessoal Técnico-Administrativo em Educação. São Luís, MA. Disponível em: <http://www.ufma.br/editais/arquivos/concurso1901o9.pdf>. Acesso em: 05 dez. 2016.

. Edital PRH № 1/2013, de 13 de dezembro de 2013. Concurso Público para Pessoal Técnico-Administrativo em Educação. São Luís, MA. Disponível em: <http://www.concursos.ufma.br/editais/o613.pdf>. Acesso em: 05 dez. 2016.

. Resolução no 121 - CONSUN, de 17 de dezembro de 2009: aprova a criação do Núcleo Pró Acessibilidade e Permanência de Pessoas com Deficiência à Educação. São Luís, MA.

Recebido em 16/o9/2018.

Aprovado em 27/11/2018. 